A measurement strategy for non-dispersive ultra-violet detection of formaldehyde in indoor air: spectral analysis and interferent gases

This content has been downloaded from IOPscience. Please scroll down to see the full text. 2016 Meas. Sci. Technol. 27015802

(http://iopscience.iop.org/0957-0233/27/1/015802)

View the table of contents for this issue, or go to the journal homepage for more

Download details:

IP Address: 138.250.27.152

This content was downloaded on 04/01/2016 at 18:25

Please note that terms and conditions apply. 


\title{
A measurement strategy for non-dispersive ultra-violet detection of formaldehyde in indoor air: spectral analysis and interferent gases
}

\author{
J J Davenport ${ }^{1,4}$, J Hodgkinson ${ }^{1,3}$, J R Saffell ${ }^{2}$ and R P Tatam ${ }^{1}$ \\ ${ }^{1}$ Engineering Photonics, Cranfield University, Cranfield, Bedfordshire MK43 0AL, UK \\ 2 Alphasense Ltd, Sensor Technology House, 300 Avenue West, Skyline 120, Great Notley, Essex CM77 \\ 7AA, UK \\ E-mail: j.hodgkinson@cranfield.ac.uk
}

Received 17 June 2015, revised 20 August 2015

Accepted for publication 14 September 2015

Published 14 December 2015

\begin{abstract}
We have conducted an extensive review of published spectra in order to identify a region with potential for detection of formaldehyde in indoor air. 85 chemicals and chemical groups common to the indoor environment were identified, 32 of which had absorption spectra in the $\mathrm{UV}-\mathrm{vis}$ region. Of these, 11 were found to overlap with the formaldehyde UV region. It was found that the region between 320 to $360 \mathrm{~nm}$ is relatively free from interference from indoor gases, with $\mathrm{NO}_{2}$ being the only major interferent. A method is proposed for a low resolution $(3 \mathrm{~nm})$ spectroscopic detection method, specifically targeted at formaldehyde absorption features at $327 \mathrm{~nm}$ with a reference at $334 \mathrm{~nm} .32 \mathrm{ppb}$ of $\mathrm{NO}_{2}$ was found to have a crosssensitivity with equivalent magnitude to $100 \mathrm{ppb}$ of formaldehyde. A second reference at $348 \mathrm{~nm}$ would reduce this cross-sensitivity.
\end{abstract}

Keywords: formaldehyde, gas sensing, non-dispersive ultra-violet, NDUV, UV spectroscopy

(Some figures may appear in colour only in the online journal)

\section{Introduction}

Formaldehyde, also known as methanal, methyl aldehyde and methylene oxide, is the first member of the aldehyde chemical family and has the chemical formula $\mathrm{CH}_{2} \mathrm{O}$. Under standard conditions it is a colourless gas. It is toxic, allergenic and a potential human carcinogen [1-3]. It has been shown to cause inflammation of lung epithelial cells [4] and to be dangerous at the ppb level (parts-per-billion, 1

${ }^{3}$ Author to whom any correspondence should be addressed.

${ }^{4}$ Now at: Biomedical Engineering Research Group, Electrical and Electronic Engineering, City University, London EC1V 0HB, UK

(c) (i) Original content from this work may be used under the terms of the Creative Commons Attribution 3.0 licence. Any further distribution of this work must maintain attribution to the author(s) and the title of the work, journal citation and DOI. molecule in $10^{9}$ of air) [5]. The World Health Organisation (WHO) has set a guideline level of prolonged formaldehyde exposure at $80 \mathrm{ppb}$, and many countries have set theirs in line with this $[6,7]$. Some countries have guideline levels as high as $100 \mathrm{ppb}$, such as Canada, Singapore and South Korea [7].

Formaldehyde is also a valuable industrial chemical with limited alternatives $[1,2,7]$. Formaldehyde resin is used as an adhesive in plywood [8,9] and in carpeting [10], and is also used in the production of paints [11] and wallpapers [12]. Emission levels are highest when products are new, generally decreasing exponentially, but can take multiple years to reach safe levels $[6,7,13]$. As a result formaldehyde gas can build up in enclosed areas and, particularly when new furnishings or carpeting have been installed, it can pose a serious risk to health. 
Table 1. Examples of some present detection methods for formaldehyde.

\begin{tabular}{|c|c|c|c|}
\hline Technique & $\begin{array}{l}\text { Response/averaging } \\
\text { time (s) }\end{array}$ & $\begin{array}{l}\text { Min detectable } \\
\text { concentration }\end{array}$ & Ref \\
\hline Fiber optic based sensing of fluorescence of chemical indicator & $\sim 100$ & $2.5 \mathrm{ppb}$ & [6] \\
\hline $\begin{array}{l}\text { Tunable diode laser spectroscopy at } 3.56 \mu \mathrm{m} \text { with a } 100 \mathrm{~m} \text { multipass } \\
\text { cell and an interband cascade laser }\end{array}$ & 1 & $3.5 \mathrm{ppb}$ & [14] \\
\hline Tunable diode laser spectroscopy at $3.53 \mu \mathrm{m}$ with a $100 \mathrm{~m}$ multipass cell & 260 & $5 \mathrm{ppt}$ & [15] \\
\hline $\begin{array}{l}\text { Tunable diode laser spectroscopy at } 3.5 \mu \mathrm{m} \text { with a } 100 \mathrm{~m} \text { multipass } \\
\text { cell and a difference frequency generation source }\end{array}$ & 60 & $74 \mathrm{ppt}$ & [16] \\
\hline $\begin{array}{l}\text { Off-axis integrating cavity output spectroscopy at } 3.53 \mu \mathrm{m} \text { with an } 83 \\
\mathrm{~m} \text { pathlength cell }\end{array}$ & 3 & $50 \mathrm{ppb}$ & [17] \\
\hline Cavity ringdown spectroscopy at $3.5 \mu \mathrm{m}$ with a $1.2 \mathrm{~km}$ pathlength cell & 2 & $2 \mathrm{ppb}$ & [18] \\
\hline Photoacoustic spectroscopy with $2 \mathrm{f}$ wavelength modulation at $3.5 \mu \mathrm{m}$ & 3 & $3 \mathrm{ppb}$ & [19] \\
\hline $\begin{array}{l}\text { Quartz-enhanced photoacoustic spectroscopy at } 3.53 \mu \mathrm{m} \text { with a } \\
5.3 \mathrm{~mm} \text { cell }\end{array}$ & 10 & $0.6 \mathrm{ppb}$ & {$[20]$} \\
\hline
\end{tabular}

Optical sensors generally offer a number of advantages for gas detection including fast response times, reliable components and, for absorption based sensors, non-contact operation. Table 1 gives some examples of reported optical detection methods for formaldehyde.

Techniques requiring chemical indicators can be difficult to implement as standalone sensors. For example the sensor of Kudo et al [6] requires circulation of a chemical reagent and $\mathrm{pH}$ buffer for correct operation, which precludes its use as a compact sensor for field use requiring minimal human intervention.

In tuneable diode laser spectroscopy (TDLS), a tuneable diode laser is used as a light source and its wavelength is tuned to scan across the absorption spectrum of the target gas. TDLS is sensitive; Wysocki et al [14] demonstrating a detection limit of $3.5 \mathrm{ppb}$ with a response time of $1 \mathrm{~s}$. Richter et al [16] achieved a greater sensitivity of $74 \mathrm{ppt}$ at $3.5 \mu \mathrm{m}$ but at a decreased response time (once per minute rather than once every few seconds). TDLS systems demonstrate good species selectivity, often with no spectral overlap between absorption lines, and excellent signal-to-noise ratios, but can expensive and complex to manufacture. This is especially true when using quantum cascade lasers (QCLs), interband cascade lasers (ICLs) or difference frequency generation (DFG) sources to access the mid infrared region. Sensitivity can be improved by the use of multipass optical cells or cavityenhanced techniques such as off-axis integrated cavity output spectroscopy (OA-ICOS) or cavity ringdown spectroscopy (CRDS), but these further add to system complexity, footprint and cost.

Photoacoustic spectroscopy (PAS) relies on the photoacoustic effect whereby sound is produced by the absorption of light from a modulated source. PAS has been shown to give reasonable sensitivity and response time (detection of formaldehyde at $3 \mathrm{ppb}$ at one measurement per three minutes being shown by Angelmahr et al [19]) but can be susceptible to background acoustic noise. The QEPAS technique, as demonstrated by Horstjann et al for formaldehyde [20], aims to solve this problem using a quadrupole acoustic sensor, however to sensitively detect formaldehyde still requires the use of a costly QCL source.
Differential optical absorption spectroscopy (DOAS) is commonly used for outdoor formaldehyde detection. It typically uses a region of the spectrum between approximately 320 and $360 \mathrm{~nm}$ [21-24] because there are several clear formaldehyde absorption peaks with relatively little interference from other outdoor gases. Stutz and Platt [25] have published algorithms required to separate measurements of concentrations of ozone, nitrogen dioxide, sulfur dioxide and formaldehyde in the atmosphere. Hausmann et al [26] have estimated the level of error when using UV DOAS techniques to measure concentrations of $\mathrm{OH}, \mathrm{SO}_{2}, \mathrm{C}_{10} \mathrm{H}_{8}$ and formaldehyde in the atmosphere, in the presence of instrumental noise. Both papers reveal a high degree of complexity in spectral post-processing required to separate these species at trace atmospheric levels using their UV absorption spectra. DOAS, like many optical spectroscopic gas detection methods, relies on high resolution (sub nanometer) spectral measurements [21].

Many of these developments have been applied to the measurement of formaldehyde in outdoor air, to understand outdoor pollution or atmospheric processes. In contrast, the indoor environment has different emission sources, and their concentrations are often higher since significant concentrations of gases can build up in enclosed areas [27]. Weschler has published a comprehensive review of the number of gases and volatiles present, identifying 85 chemical species and families [27]. To enable reliable measurements of formaldehyde in the indoor environment, it is therefore important to consider the role of spectral interference for the mixture of gases commonly found in indoor air. This is especially true of measurements made in the UV region, where such effects can often be the limiting factor.

Dooly et al [28] have shown the corrections required to measure NO concentrations in the presence of other vehicle exhaust gases, in particular including UV-absorbing species $\mathrm{NO}_{2}$ and $\mathrm{SO}_{2}$. A high resolution $(0.7 \mathrm{~nm})$ spectrometer was used for this work. Absorbances at a wavelength of $227 \mathrm{~nm}$ had to be corrected by measurements made at 287 and $413 \mathrm{~nm}$ to account for the presence of two additional absorbing species. Use of narrow spectral bins simplified the analysis required by limiting the range of potential interferents at each wavelength. Nevertheless, some cross-response to the interfering species remained. 


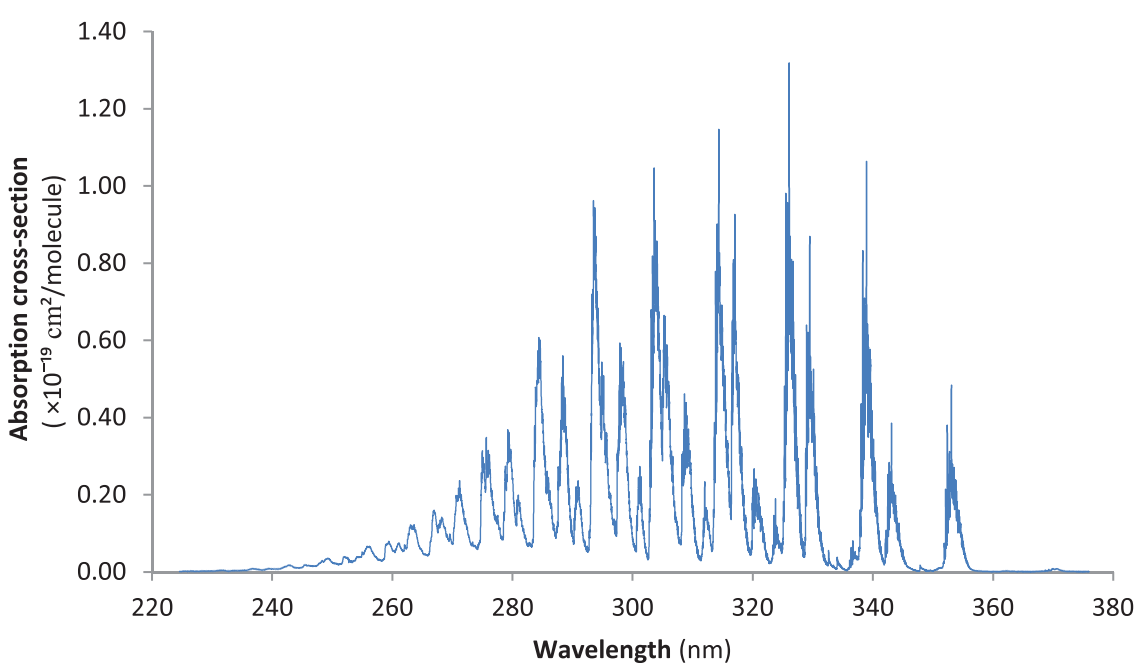

Figure 1. Formaldehyde absorption spectrum in the UV range, re-plotted from the data of Meller et al [30]. Peaks are not fully resolved at the resolution of this spectrum $(0.01 \mathrm{~nm})$.

In this paper, consideration is made of the UV absorption spectra of a range of gases commonly found in the indoor environment, finding that the $320-360 \mathrm{~nm}$ region (as used in DOAS) is also appropriate for indoor air. For chemical species selectivity, previous work shows that high resolution spectral measurements are often required, especially in the UV region where spectra from multiple species can overlap. In contrast, a proposal is described here for a lower resolution $(3 \mathrm{~nm})$ formaldehyde detection method, taking advantage of features of the formaldehyde absorption spectrum. Measurement and reference channels are selected to give a formaldehyde-specific detection method with the potential for a greatly simplified system suitable for measurement of formaldehyde in the indoor environment. The anticipated level of cross-sensitivity has been quantified for potentially interfering gases present at levels typical of the indoor environment.

The method described here has a number of advantages over current systems that it shares with non-dispersive infrared gas detection (NDIR), including simplicity of manufacture, requirement of few, low cost components and a small size [29]. It follows similar principles to NDIR except that it operates in the ultra-violet region of the spectrum. It permits low resolution measurements targeted at specific features of the absorption spectra of the gases being analyzed. This is only possible with a detailed understanding of the environment being tested and the spectra of the species common to it, and only if a spectral region can be identified where interference is minimal.

\section{Spectroscopy theory}

Photons passing through a sample of gas can only be absorbed when they match a specific energy transition of the molecules present. Absorption is related to gas concentrations and is given by the Beer-Lambert law:

$$
\frac{I(\lambda)}{I_{0}(\lambda)}=\mathrm{e}^{-\sigma(\lambda I N)}
$$

where $I$ is the final intensity of light transmitted through a sample at wavelength $\lambda, I_{0}$ is the initial intensity at that wavelength, $\sigma$ is the absorption cross-section per molecule of absorbing gas at that wavelength, $l$ is the light path length through the sample and $N$ is the number density of absorbing gas molecules. Absorbance is a term defined as the ratio of absorbed intensity to initial intensity, given by equation (2). It has units AU (absorption units) which are dimensionless.

$$
\frac{\Delta I(\lambda)}{I_{0}(\lambda)}=\frac{I_{0}(\lambda)-I(\lambda)}{I_{0}(\lambda)}=1-\mathrm{e}^{-\sigma(\lambda) I N} .
$$

At low values of $\sigma l N$, this approximates to the linear form:

$$
\frac{\Delta I(\lambda)}{I_{0}(\lambda)}=\sigma(\lambda) l N .
$$

The UV absorption spectrum of formaldehyde is shown in figure 1.

When two or more species are present that absorb at the same wavelength, their absorption cross-sections in equation (1) are additive. It is not always possible to isolate individual absorption spectra from the spectrum of a complicated sample. In this report the UV absorption spectrum of formaldehyde is compared to those of gases likely to be present in indoor environments in an attempt to understand and minimize spectral interference.

\section{Gases present in indoor air}

The substances considered in this review were predominantly based on a comprehensive study of pollutants in indoor air by Weschler [27]. Weschler's study focused mainly on homes in the United States and collected and compared published data from many other studies. Some of the underlying data in these sources was obtained using detection methods such as gas chromatographs linked to mass spectrometers [31, 32]. Other data was inferred from the presence of emitting materials such as medium density fiber board (MDF). 
Many of the above gas detection methods take multiple hours to run $[33,34]$ and so short-lived species may have gone undetected and been left out of Weschler's study. One such compound, nitrous acid, is produced from the heterogeneous hydrolysis of nitrogen dioxide with wet surfaces [35] and has been found to persist for around $10 \mathrm{~min}$ in forest atmospheres [36]. The nitrous acid absorption spectrum does interfere with formaldehyde, as described later in this paper.

Several other studies had found nitrous acid to be present in the indoor environment $[35,37]$ and so it was added to the list of compounds considered here. Otherwise, Weschler's report appears to be comprehensive and is well regarded by several other authors $[7,38]$. It has therefore been used as the bench mark for formaldehyde selectivity in this paper.

The substances identified for this review can be divided into three basic categories: inorganic gases, volatile organic compounds (including semi-volatiles) and airborne particles. Each of these categories has some broadly similar properties and gases in a category will frequently have similar sources. The general properties and sources of these categories are discussed below.

The source of many inorganic gases in modern buildings is cooking and heating appliances [39] as well as indoor smoking and various industrial processes. In the UK, indoor concentrations of carbon monoxide, nitrogen dioxide and nitric oxide have been on the decrease in recent years due to a decrease in smoking and other factors [27, 40, 41]. The trend of indoor ozone is less clear [42].

The category 'volatile organic compounds' covers a wide variety of large, organic molecules that can still readily be gaseous at room temperature. Formaldehyde is a volatile organic compound, as are some other members of the aldehyde chemical group. This category also includes alkanes, aromatics such as benzene and toluene and many more.

Indoor sources of these gases include emissions from resins, rubber and carpets, smoking and indoor chemical reactions $[27,43]$. Indoor concentrations of some compounds such as aromatics and some of the more volatile compounds, are currently decreasing or remaining constant due to decreases in source abundance [44-46]. Some of the longer-chain aldehydes and many semi-volatile organic compounds are currently on the increase, potentially due to increases in preceding reactions and increases in certain cosmetic products [27, 47, 48].

The final category includes metal particles, mineral fibers, dust components, mould spores and many others [27]. Their sources are widespread, including lead-based paints, indoor smoking, industrial processes and even human skin. The concentrations of many airborne particles are decreasing due to legal restrictions on certain sources, but it is difficult to draw general trends [27, 49, 50].

Small particles are known to exhibit a spectroscopic scattering effect that is analogous to the absorption cross-section in the Beer-Lambert law. It is variable with wavelength and so airborne particles can exhibit broad spectral features similar to light absorption features [51]. Some airborne particles also exhibit fluorescence effects in the UV [51, 52]. Airborne particles were not considered in this project but may have to be considered or eliminated when using a detection system 'in situ', potentially by filtering. Many gas detectors, for example those based on non-dispersive infrared detection, are based on gas diffusion into the optical path through a particulate filter [29].

\section{Results of spectral survey}

A full list of all substances and substance groups considered in this survey is given in table 2. In total 85 substances and substance groups were identified, 32 of which had absorption spectra in the UV-vis region. Of these, 11 were found to overlap with the formaldehyde UV absorption region. References are given for the UV spectral data found for these substances.

Figure 2 shows the absorption spectra of the 11 gases identified to overlap with formaldehyde. The spectrum of formaldehyde is included for comparison. Data have all been converted to absorbance as defined in equation (2) for concentrations of 100 $\mathrm{ppb}$ and a path length of $100 \mathrm{~mm}$, for comparison. Interference may come from a mix of organic and inorganic gases. The aldehyde group is represented here, as are some aromatics.

On examining this data, the spectral region between 320 and $360 \mathrm{~nm}$ was identified as having very limited spectral interference from other gases (highlighted in figure 2). Most of the potentially interfering species did not have significant absorption in this region, and some of the highest formaldehyde absorption peaks can be found here. Nitrogen dioxide appears to be the most significant source of interference in this region, with some interference from nitrous acid as well. This was a surprising result given the number of species considered.

\section{Proposed detection method}

We propose a method for formaldehyde detection based on non-dispersive spectroscopy using the absorption region identified above. Non-dispersive spectroscopy uses elements such as bandpass filters to limit the wavelengths reaching detectors [79]. This removes the need for dispersive elements such as optical gratings. A diagram of a typical non-dispersive spectroscopic system is shown in figure 3 .

Light from the source passes through the sample. The gases present in the sample absorb light in accordance with equation (2) and their own absorption spectra. Band pass filters isolate regions of the spectrum corresponding to specific features of the formaldehyde absorption spectrum. Finally the intensity of light within those wavelength bands are measured by the detector elements. The concentration of formaldehyde can be found from the relative intensities of light measured at the detector elements.

One filter is selected in a range of high formaldehyde absorption as a detection channel and a second in a range of little or no absorption as a reference channel. This allows the formaldehyde concentration to be calculated by the following equation derived from the Beer-Lambert law [29]:

$$
S=1-\frac{I_{\mathrm{D}}}{I_{\mathrm{R}}} \frac{I_{\mathrm{R}, 0}}{I_{\mathrm{D}, 0}}
$$

where $S$ is the normalized absorbance signal, $I$ denotes intensity, subscript $\mathrm{D}$ denotes detection channel, subscript $\mathrm{R}$ denotes reference channel and subscript 0 denotes clean air measurements taken at a different time. 
Table 2. List of all substances and substance groups considered in this survey

\begin{tabular}{|c|c|}
\hline Substance & Reference \\
\hline \multicolumn{2}{|l|}{ Inorganic gases } \\
\hline Carbon monoxide & {$[53]$} \\
\hline Nitrogen dioxide & {$[54]$} \\
\hline Nitric oxide & {$[55]$} \\
\hline Nitrous acid & [76] \\
\hline Ozone & {$[56]$} \\
\hline Sulfur dioxide & {$[57]$} \\
\hline Radon & a \\
\hline \multicolumn{2}{|c|}{ Very volatile organic compounds (VVOC) } \\
\hline Formaldehyde & {$[30]$} \\
\hline Acetaldehyde & {$[58]$} \\
\hline Acrolein & [59] \\
\hline 1,3-Butadiene & {$[60]$} \\
\hline Isoprene & {$[61]$} \\
\hline \multicolumn{2}{|c|}{ Volatile organic compounds (VOC), aldehydes } \\
\hline Hexanal & a \\
\hline Nonanal & a \\
\hline Decanal & {$[62]$} \\
\hline \multicolumn{2}{|l|}{ VOC, aliphatics } \\
\hline n-Alkanes (e.g. n-octane) & {$[63]$} \\
\hline Branched & a \\
\hline Undecane & a \\
\hline \multicolumn{2}{|l|}{ VOC, aromatics } \\
\hline Benzene & {$[64,65]$} \\
\hline Toluene & [66] \\
\hline Xylene isomers & {$[64,65]$} \\
\hline Ethylbenzene & {$[67]$} \\
\hline Trimethylbenzene isomers & {$[64,65]$} \\
\hline Styrene & [67] \\
\hline \multicolumn{2}{|l|}{ VOC, terpenoids } \\
\hline Limonene & $\mathrm{a}$ \\
\hline$\alpha$-Pinene & [68] \\
\hline Linalool & a \\
\hline$\alpha$-Terpineol & $\mathrm{a}$ \\
\hline \multicolumn{2}{|l|}{ VOC, chlorinated } \\
\hline Dichloromethane & $\mathrm{a}$ \\
\hline Chloroform & [69] \\
\hline Carbon tetrachloride & a \\
\hline 1,1,1-Trichloromethane & [69] \\
\hline Trichloroethylene & a \\
\hline Tetrachloroethylene (Perc) & a \\
\hline Dichlorobenzene & [70] \\
\hline Dichlorophenols & a \\
\hline \multicolumn{2}{|l|}{ VOC, fluorinated } \\
\hline Freon 11 & [71] \\
\hline Freon 12 & [72] \\
\hline Freon 113 & [73] \\
\hline \multicolumn{2}{|l|}{ VOC, other } \\
\hline Dimethyl phthalate & $\mathrm{a}$ \\
\hline Diethyl phthalate & a \\
\hline Cyclopentasiloxane (D5) & a \\
\hline
\end{tabular}

(Continued)
Table 2. (continued)

\begin{tabular}{|c|c|}
\hline Substance & Reference \\
\hline \multicolumn{2}{|c|}{ Semivolatile organic compounds (SVOC) } \\
\hline Triclosan & a \\
\hline Bis(tributyltin)oxide(TBTO) & $\mathrm{a}$ \\
\hline Butylated hydroxytoluene (BHT) & a \\
\hline Pentachlorophenol (PCP) & a \\
\hline Trichlorophenols & a \\
\hline \multicolumn{2}{|l|}{ SVOC, combustion byproducts } \\
\hline ETS & $\mathrm{a}$ \\
\hline Dioxins & a \\
\hline Furans & a \\
\hline PAHs & a \\
\hline \multicolumn{2}{|l|}{ SVOC, degradation products } \\
\hline Bisphenol-A & a \\
\hline \multicolumn{2}{|l|}{ SVOC, flame-retardants } \\
\hline BDE-47 & a \\
\hline BDE-99 & a \\
\hline BDE-209 & a \\
\hline Tris(chloropropyl)phosphate & a \\
\hline \multicolumn{2}{|l|}{ SVOC, heat transfer fluids } \\
\hline PCBs & a \\
\hline Polydimethyl siloxanes & a \\
\hline \multicolumn{2}{|l|}{ SVOC, personal care products } \\
\hline Musk compounds & a \\
\hline \multicolumn{2}{|l|}{ SVOC, pesticides \& herbicides } \\
\hline Aldrin & $\mathrm{a}$ \\
\hline Chlordane & $\mathrm{a}$ \\
\hline Chlorpyrifos & $\mathrm{a}$ \\
\hline DDT & [74] \\
\hline DDE & a \\
\hline Dieldrin & $\mathrm{a}$ \\
\hline Malathione & $\mathrm{a}$ \\
\hline Mirex & $\mathrm{a}$ \\
\hline Permethrin & a \\
\hline \multicolumn{2}{|l|}{ SVOC, plasticizers } \\
\hline Dibutyl phthalate & [61] \\
\hline Butylbenzyl phthalate & a \\
\hline Di-2-ethylhexyl phthalate & a \\
\hline Triphenylphosphate (TPP) & {$[75]$} \\
\hline \multicolumn{2}{|l|}{ SVOC, stain and water repellents } \\
\hline Perfluorinated surfactants & a \\
\hline \multicolumn{2}{|c|}{ SVOC, nonionic surfactants and coalescing agents } \\
\hline 4-Nonylphenol & a \\
\hline Texanol_isomers & $\mathrm{a}$ \\
\hline \multicolumn{2}{|l|}{ SVOC, waxes and polishes } \\
\hline Fatty acids & a \\
\hline Sesquiterpenes & a \\
\hline \multicolumn{2}{|l|}{ Metals and mineral fibers } \\
\hline Asbestos & a \\
\hline Cadmium & a \\
\hline Lead & a \\
\hline Mercury & a \\
\hline \multicolumn{2}{|l|}{ Others } \\
\hline $\begin{array}{l}\text { Allergens (from mites, pets, etc.) } \\
\text { Mold/fungi } \\
\text { Airborne particles }\end{array}$ & \\
\hline
\end{tabular}

${ }^{a}$ We were unable to find reported UV absorption spectra for the gas/vapour form 

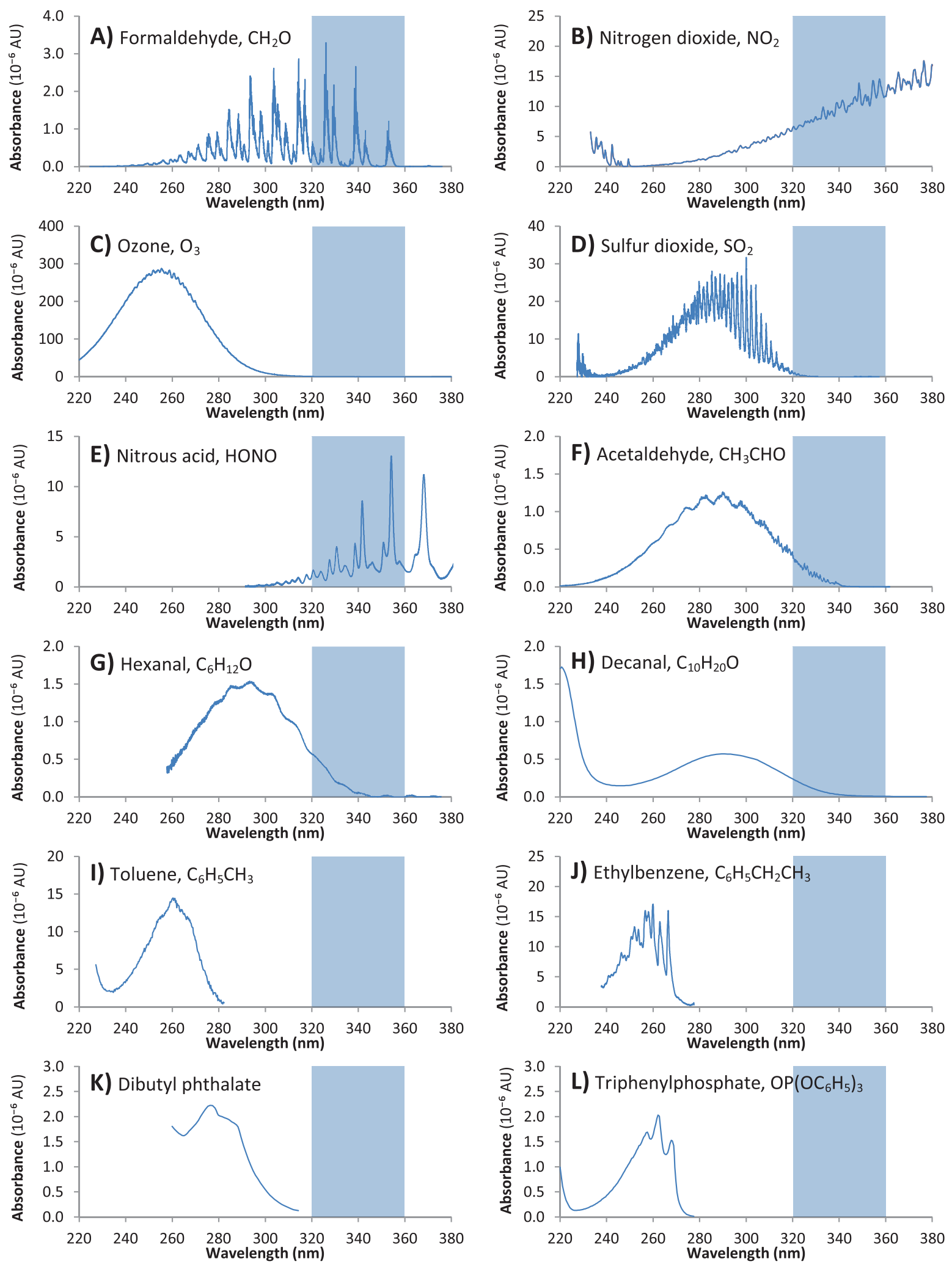

Figure 2. Re-plotted absorbance spectra of identified gases $(220-380 \mathrm{~nm})$ assuming $100 \mathrm{ppb}$ concentrations and $100 \mathrm{~mm}$ path lengths. (A) $\mathrm{CH}_{2} \mathrm{O}$ [30] (B) $\mathrm{NO}_{2}$ [54] (C) $\mathrm{O}_{3}$ [56] (D) $\mathrm{SO}_{2}$ [57] (E) $\mathrm{HONO}$ [76] (F) $\mathrm{CH}_{3} \mathrm{CHO}$ [77] (G) $\mathrm{C}_{6} \mathrm{H}_{12} \mathrm{O}$ [78] (H) $\mathrm{C}_{10} \mathrm{H}_{20} \mathrm{O}$ [62] (I) $\mathrm{C}_{6} \mathrm{H}_{5} \mathrm{CH}_{3}$ [66] (J) $\mathrm{C}_{6} \mathrm{H}_{5} \mathrm{CH}_{2} \mathrm{CH}_{3}[67](\mathrm{K}) \mathrm{C}_{6} \mathrm{H}_{4}\left(\mathrm{OCOC}_{4} \mathrm{H}_{9}\right)_{2}$ [61] (L) $\mathrm{OP}\left(\mathrm{OC}_{6} \mathrm{H}_{5}\right)_{3}$ [75].

The third channel is an additional reference channel selected in a range of little or no absorption. Along with the first reference channel, it can be used for identifying a known interfering species such as $\mathrm{NO}_{2}$. The equivalent absorbance of
$\mathrm{NO}_{2}$ can be calculated and subtracted from the formaldehyde measurement. Provided formaldehyde and $\mathrm{NO}_{2}$ concentrations are the only relevant variables, they can both be determined by three carefully selected measurements. 


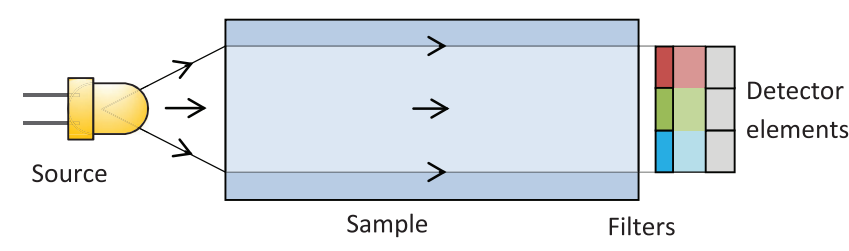

Figure 3. Diagram of a typical non-dispersive spectroscopy system. Light from the source passes through the sample. The filters limit light reaching the detector elements to specific wavelength bands.

The placement of the three channels was based on the absorption spectra of formaldehyde and other potentially interfering gases identified in table 2 . The formaldehyde absorption region between 320 and $360 \mathrm{~nm}$ shows a number of high absorption regions and some regions with minimal absorption. These regions of minimal absorption are peculiar to formaldehyde, with many interfering gases having a more gradual transition between high absorption and low absorption. These unusual features allow for reference channels and detection channels to be placed very close together on the formaldehyde spectrum.

Figure 4 shows the formaldehyde spectrum in the identified region, along with some example detection channels, being mathematically determined Gaussian transmission spectra with full width half maximum (FWHM) of $3 \mathrm{~nm}$. Narrow band-pass filters frequently have approximately Gaussian spectra and a $3 \mathrm{~nm}$ FWHM is common to laser-line filters [80]. A detection channel covers a region of high absorption and two reference channels cover regions of low absorption. Figure 5 shows the relative intensity change across each channel calculated for a concentration of $10 \mathrm{ppm}$ and a $1 \mathrm{~m}$ gas cell, compared to the case for no absorption (clean air).

The total equivalent absorbances of these four example channels were found to be A: $9.0 \times 10^{-4} \mathrm{AU}, \mathrm{B}: 6.1 \times 10^{-5}$ AU, C: $2.3 \times 10^{-5}$ AU. The absorbances from the detection channel A was more than a factor of 10 higher than for reference channels B and C.

Using a reference channel as the initial intensity and a detection channel as the final intensity, the absorbance of a sample can be found in real time. The reference channel allows fluctuations in source intensity and other changes to be compensated. Using channel A as a detection channel (giving $I_{\mathrm{D}}$ in equation (4)) and channel B as a reference channel (giving $I_{R}$ in equation (4)), $10 \mathrm{ppm}$ of formaldehyde in a $1 \mathrm{~m}$ gas cell has a calculated equivalent absorbance of $4.2 \times 10^{-4} \mathrm{AU}$. This assumes that the light source is ideally 'white', i.e. has a flat spectral output, additional scaling factors being required if it is not.

\section{Results}

In order to verify the effectiveness of this theoretical method, the effective absorbances of expected interfering species were calculated using the method of section 5, with channel A as a detection channel and channel B as a reference. Spectral data was used from the same sources as for figure 2. Typical concentrations were used in the calculation, as found in indoor air in previous studies. The results are given in table 3 . Note that some species give a 'negative absorbance', where they absorb more strongly in the reference region than in the detection region. Also given is the concentration required to give a signal level equivalent to that of $100 \mathrm{ppb}$ formaldehyde. For most species the required concentration is significantly above the typical value. $\mathrm{NO}_{2}$ is expected to be the most significant interfering species for this method, as the required concentration is $-32 \mathrm{ppb}\left(\mathrm{NO}_{2}\right.$ exhibits an apparent negative absorbance with our proposed detection scheme), which is of a similar order of magnitude to the level that can be found in indoor air.

The cross-sensitivity of nitrogen dioxide would be further reduced by using a second reference channel at $348 \mathrm{~nm}$ (channel $\mathrm{C}$ in section 5) at which the formaldehyde absorbance is minimal. A measurement system would then have 3 data points from the three measurement channels and 3 unknowns, ie the lamp intensity and concentrations of formaldehyde and nitrogen dioxide. Using channel $\mathrm{C}$ as a measurement channel (giving $I_{\mathrm{D}}$ in equation (4)) and channel B as a reference channel (giving $I_{\mathrm{D}}$ in equation (4)), a concentration of $20 \mathrm{ppb}$ of nitrogen dioxide was calculated to give an absorbance of $5.6 \times 10^{-7} \mathrm{AU}$. Thus, the concentration of nitrogen dioxide can be found simultaneously to formaldehyde measurements and its effect on the formaldehyde measurement (using channels A and B) subtracted according to the cross-sensitivity shown in table 3 .

Measuring nitrogen dioxide in this manner is also potentially susceptible to interference. The only identified species with significant absorption in channels $\mathrm{B}$ and $\mathrm{C}$ besides $\mathrm{NO}_{2}$ was nitrous acid (see figure 2). Calculating the cross sensitivity of 16 ppb nitrous acid [37] over channels $\mathrm{C}$ and $\mathrm{B}$ as detection and reference respectively, gives an absorbance of $2.9 \times 10^{7}$ $\mathrm{AU}$, or half that of $20 \mathrm{ppb}$ of $\mathrm{NO}_{2} .16 \mathrm{ppb}$ nitrous acid would therefore give the same results as $10 \mathrm{ppb} \mathrm{NO}$ and result in an error when applying the $\mathrm{NO}_{2}$ compensation scheme described above. The level of error in this worst case scenario would be an unwanted subtraction from the formaldehyde measurement of $10 \mathrm{ppb} \times 100 / 32=30 \mathrm{ppb}$, which is below the required action limit for formaldehyde. We expect nitrous acid to be present in such large quantities only in particular circumstances, since it is both short-lived and produced on wet or damp surfaces.

Alternatively, other low cost measurement technologies for $\mathrm{NO}_{2}$ are in common use and may be used to compensate the formaldehyde measurement for $\mathrm{NO}_{2}$ cross-sensitivity. For example, electrochemical cells are available with a limit of detection for $\mathrm{NO}_{2}$ of $6 \mathrm{ppb}(1 \sigma)$ [84].

\section{Conclusions}

The UV region $320-360 \mathrm{~nm}$ is known to be used for the spectroscopic measurement of formaldehyde in forest and outdoor environments by DOAS. However, its potential for detection in indoor air is not well established. This is partly due to the increased potential range of spectral interferents and differing (often higher) concentrations present.

By considering 85 substances and substance groups, we identified the region of the formaldehyde spectrum between 320 and $360 \mathrm{~nm}$ as having minimal spectral interference in the indoor environment. The only significant interference comes from nitrogen dioxide. The region includes some areas with 


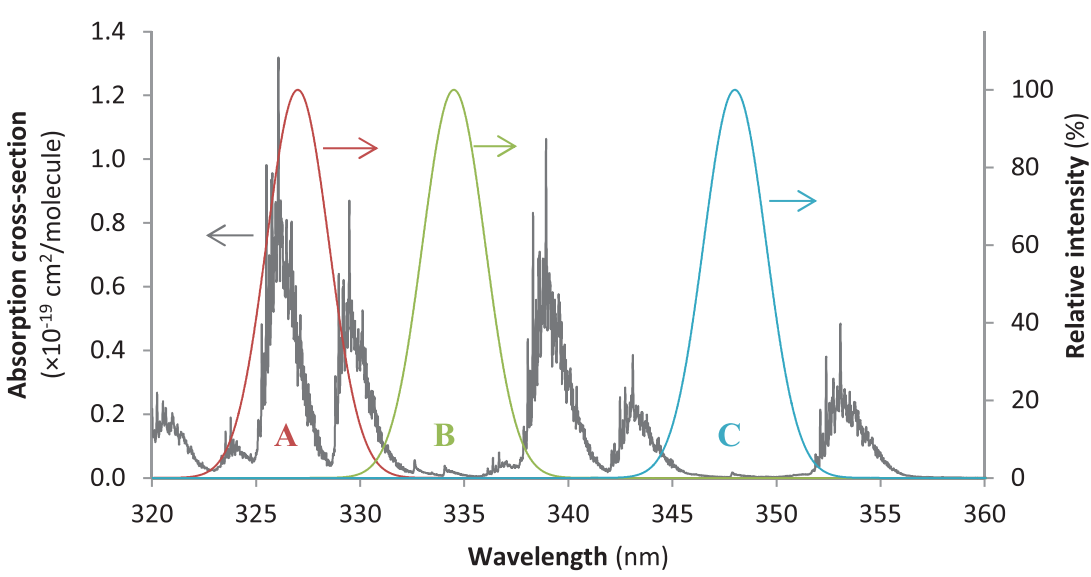

Figure 4. Example channels as mathematically determined Gaussian distributions with bandwidths of $3 \mathrm{~nm}$ (FWHM) and arbitrarily selected intensity, superposed with the absorption cross-section of formaldehyde. (A) detection channel, (B) reference channel, (C) reference channel.

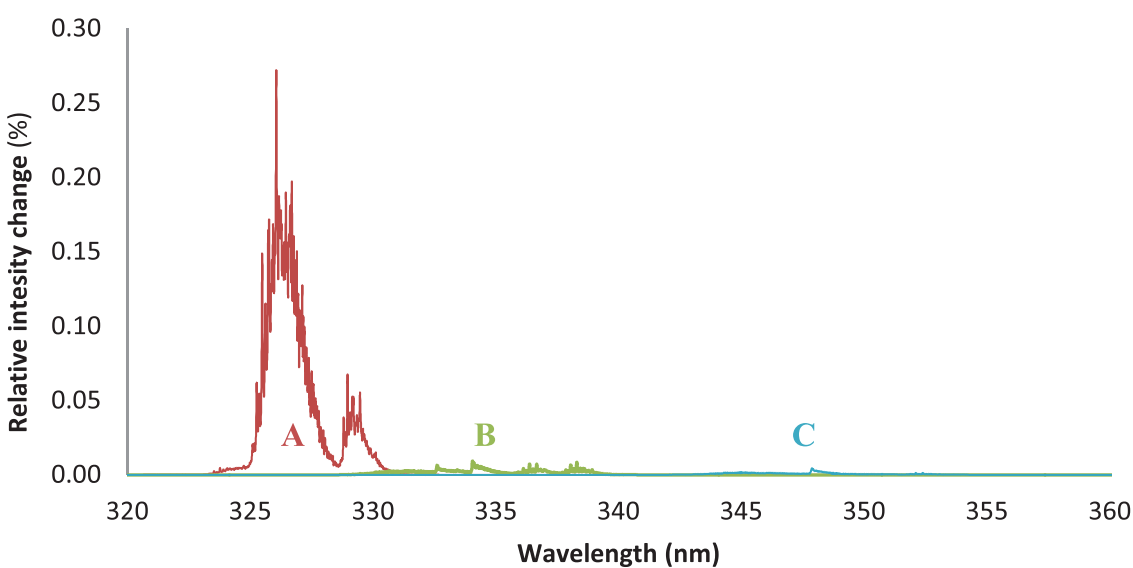

Figure 5. Relative intensity change across each channel calculated for $10 \mathrm{ppm}$ formaldehyde and a $1 \mathrm{~m}$ gas cell. The detection channel A show significantly greater change in intensity with formaldehyde concentration than the reference channels B and D.

Table 3. Calculated absorbances of expected interference when using channels A and B from figure 4 and based on spectral data and typical indoor concentrations from the literature. A $1 \mathrm{~m}$ path length has been used for all absorbances calculated for this table.

\begin{tabular}{lccc}
\hline & & & $\begin{array}{c}\text { Concentration giving } \\
\text { absorbance equivalent to } \\
100 \mathrm{ppb} \mathrm{CH}_{2} \mathrm{O} / \mathrm{ppb}\end{array}$ \\
\hline Fpecies & Typical concentration/ppb & Calculated absorbance/AU & 100 \\
Nitrogen dioxide $\mathrm{NO}_{2}$ & 100 (reference value) & $4.2 \times 10^{-6}$ & -32 \\
Ozone $\mathrm{O}_{3}$ & $20[81]$ & $-2.6 \times 10^{-6}$ & 230 \\
Sulfur dioxide $\mathrm{SO}_{2}$ & $25[81]$ & $4.6 \times 10^{-7}$ & 230 \\
Nitrous acid $\mathrm{HONO}_{\text {Acetaldehyde } \mathrm{CH}_{3} \mathrm{CHO}}$ & $1.7[81]$ & $3.0 \times 10^{-8}$ & 1400 \\
Hexanal $\mathrm{C}_{6} \mathrm{H}_{12} \mathrm{O}$ & $16[37]$ & $4.9 \times 10^{-8}$ & 2100 \\
Decanal $\mathrm{C}_{10} \mathrm{H}_{20} \mathrm{O}$ & $28[82]$ & $5.6 \times 10^{-8}$ & 210 \\
\hline
\end{tabular}

high formaldehyde absorption and some areas where absorption is minimal.

We propose the use of detection and reference channels centered at 327 and $334 \mathrm{~nm}$ respectively. With this scheme, the concentration of nitrogen dioxide giving an absorption signal of equivalent magnitude to $100 \mathrm{ppb}$ formaldehyde was found to be $32 \mathrm{ppb}$. Use of a second reference channel at $348 \mathrm{~nm}$ would minimize the contribution from $\mathrm{NO}_{2}$. This method would require relatively few, simple components giving a spectroscopic gas detector specifically targeted at formaldehyde.

\section{Acknowledgments}

This work was funded by the Engineering and Physics Science Research Council (EPSRC) under grants GR/T18424, EP/ 
P504880 and EP/H02252X. Enquiries for access to the data referred to in this article should be directed to researchdata@ cranfield.ac.uk

\section{References}

[1] Lu Y, Liu J, Lu B, Jiang A and Wan C 2010 Study on the removal of indoor VOCs using miotechnology J. Hazardous Mater. 182 204-9

[2] Kim S 2010 Control of formaldehyde and TVOC emission from wood-based flooring composites at various manufacturing processes by surface finishing J. Hazardous Mater. 176 14-19

[3] Nielsen G D and Wolkoff P 2010 Cancer effects of formaldehyde: a proposal for an indoor air guideline value Arch. Toxicol. 84 423-46

[4] Persoz C, Achard S, Leleu C, Momas I and Seta N 2010 An in vitro model to evaluate the inflammatory response after gaseous formaldehyde exposure of lung epithelial cells Toxicol. Lett. 195 99-105

[5] Rock F, Barsan N and Weimar U 2010 System for dosing formaldehyde vapor at the ppb level Meas. Sci. Technol. 21 115201

[6] Kudo H, Suzuki Y, Gessei T, Takahashi D, Arakawa T and Mitsubayashi K 2010 Biochemical gas sensor (bio-sniffer) for ultrahigh-sensitive gaseous formaldehyde monitoring Biosens. Bioelecton. 26 854-8

[7] Salthammer T, Mentese S and Marutzky R 2010 Formaldehyde in the indoor environment Chem. Rev. 110 2536-72

[8] Jiang T, Gardner D J and Baumann M G D 2002 Volatile organic compound emissions arising from the hot-pressing of mixed-hardwood particleboard Forest Prod. J. 52 66-7

[9] Risholm-Sundman M, Larsen A, Vestin E and Weibull A 2007 Formaldehyde emission-comparison of different standard methods Atmos. Environ. 41 3193-202

[10] Weschler C J, Brauer M and Michael P K 1992 Indoor ozone and nitrogen dioxide: a potential pathway to the generation of nitrate radicals, dinitrogen pentaoxide, and nitric acid indoors Environ. Sci. Technol. 26 179-84

[11] Chang J C S, Fortmann R, Roache N and Lao H C 1999 Evaluation of low-VOC latex paints Indoor Air-Int. J. Indoor Air Qual. Clim. 9 253-8

[12] Nicolas M, Ramalho O and Maupetit F 2007 Reactions between ozone and building products: impact on primary and secondary emissions Atmos. Environ. 41 3129-38

[13] Zinn T W, Cline D and Lehmann W F 1990 Long-term study of formaldehyde emission decay from particleboard Forest Prod. J. 40 15-8

[14] Wysocki G, Bakhirkin Y, So S, Tittel F K, Hill C J, Yang R Q and Fraser M P 2007 Dual interband cascade laser based trace-gas sensor for environmental monitoring Appl. Opt. $468202-10$

[15] Weibring P, Richter D, Fried A, Walega J G and Dyroff C 2006 Ultra-high-precision mid-IR spectrometer: II. System description and spectroscopic performance Appl. Phys. B 85 207-18

[16] Richter D, Fried A, Wert B P, Walega J G and Tittel F K 2002 Development of a tunable mid-IR difference frequency laser source for highly sensitive airborne trace gas detection Appl. Phys. B 75 281-8

[17] Miller J H, Bakhirkin Y A, Ajtai T, Tittel F K, Hill C J and Yang R Q 2006 Detection of formaldehyde using off-axis integrated cavity output spectroscopy with an interband cascade laser Appl. Phys. B 85 391-6

[18] Dahnke H, vonBasum G, Kleinermanns K, Hering P and Mürtz M 2002 Rapid formaldehyde monitoring in ambient air by means of mid-infrared cavity leak-out spectroscopy Appl. Phys. B 75 311-16
[19] Angelmahr M, Miklos A and Hess P 2006 Photoacoustic spctroscopy of formaldehyde with tunable laser radiation at the parts per billion level Appl. Phys. B 85 285-8

[20] Horstjann M, Bakhirkin Y A, Kosterev A A, Curl R F, Tittel F K, Wong C M, Hill C J and Yang R Q 2004 Formaldehyde sensor using interband cascade laser based quartz-enhanced photoacoustic spectroscopy Appl. Phys. B 79 799-803

[21] Winer A M 1994 Long pathlength differential optical absorption spectroscopy (DOAS) measurements of gaseous $\mathrm{HONO}, \mathrm{NO}_{2}$ and $\mathrm{HCHO}$ in the California South coast air basin Res. Chem. Intermediates 20 423-45

[22] Thomas W, Hegels E and Slijkhuis S 1998 Detection of biomass burning combustion products in Southeast Asia from backscatter data taken by the GOME spectrometer Geophys. Res. Lett. 25 1317-20

[23] DeSmedt I, Muller J F, Stavrakou T, R. Van Der A, Eskes H and Roozendael M V 2008 Twelve years of global observations of formaldehyde in the troposphere using GOME and SCIAMACHY sensors Atmos. Chem. Phys. 8 4947-63

[24] Wittrock F, Richter A, Oetjen H, Burrows J P, Kanakidou M, Myriokefalitakis S, Volkamer R, Beirle S, Platt U and Wagner T 2006 Simultaneous global observations of glyoxal and formaldehyde from space Geophys. Res. Lett. 33 L16804

[25] Stutz J and Platt U 1996 Numerical analysis and estimation of the statistical error of differential optical absorption spectroscopy measurements with least-squares methods Appl. Opt. 35 6041-53

[26] Hausmann M, Brandenburger U and Brauers T 1999 Simple Monte Carlo methods to estimate the spectra evaluation error in differential-optical-absorption spectroscopy Appl. Opt. 38 462-75

[27] Weschler C J 2009 Changes in indoor pollutants since the 1950s Atmos. Environ. 43 153-69

[28] Dooly G, Fitzpatrick C and Lewis E 2008 Deep UV based DOAS system for the monitoring of nitric oxide using ratiometric separation techniques Sensors Actuators B $134317-23$

[29] Hodgkinson J, Smith R, Ho W O, Saffell R S and Tatam R P 2013 Non-dispersive infra-red (NDIR) measurement of carbon dioxide at $4.2 \mu \mathrm{m}$ in a compact and optically efficient sensor Sensors Actuators B 186 580-8

[30] Meller R and Moortgat G K 2000 Temperature dependence of the absorption cross sections of formaldehyde between 223 and $323 \mathrm{~K}$ in the wavelength range $225-375 \mathrm{~nm}$ J. Geophys. Res.-Atmos. 105 7089-101

[31] Wisthaler A, Tamas G, Wyon D P, Strom-Tejsen P, Space D, Beauchamp J, Hansel A, Mark T D and Weschler C J 2005 Products of ozone-initiated chemistry in a simulated aircraft environment Environ. Sci. Technol. 39 4823-32

[32] Nøjgaard J, Nørgaard A and Wolkoff P 2007 On-line analysis of secondary ozonides from cyclohexene and D-limonene ozonolysis using atmospheric sampling Townsend discharge ionization mass spectrometry Atmos. Environ. 41 8345-54

[33] Pal R and Kim K 2008 Gas chromatographic approach for the determination of carbonyl compounds in ambient air Microchem. J. 90 147-58

[34] Bagheri H, Ghambarian M, Salemi A and Es-Haghi A 2009 Trace determination of free formaldehyde in DTP and DT vaccines and diphtheria-tetanus antigen by single drop microextraction and gas chromatography-mass spectrometry J. Pharmaceutical Biomed. Anal. 50 287-92

[35] Ramazan K A, Syomin D and Finlayson-Pitts B J 2004 The photochemical production of HONO during the heterogeneous hydrolysis of NO Phys. Chem. Chem. Phys. 6 3836-43

[36] Sorgel M, Trebs I, Serafimovich A, Moravek A, Held A and Zetzsch C 2011 Simultaneous HONO measurements in and above a forest canopy: influence of turbulent exchange on mixing ratio differences Atmos. Chem. Phys. 11 841-55 
[37] Park S S, Hong J H, Lee J H, Kim Y J, Cho S Y and Kim S J 2008 Investigation of nitrous acid concentration in an indoor environment using an in situ monitoring system Atmos. Environ. 42 6586-96

[38] Rudel R A and Perovich L J 2009 Endocrine disrupting chemicals in indoor and outdoor air Atmos. Environ. 43 170-81

[39] Raw G J, Coward S K D, Brown V M and Crump D R 2004 Exposure to air pollutants in English homes $J$. Exposure Anal. Environ. Epidemiol. 14 S85-94

[40] Shair F H and Heitner K L 1974 Theoretical model for relating indoor pollutant Environ. Sci. Technol. 8 444-51

[41] Mott J A, Wolfe M I, Alverson C J, Macdonald C S, Bailey C R, Ball L B, Moorman J E, Somers J H, Mannino D M and Redd S C 1974 National vehicle emissions policies and practices and declining US carbon monoxide-related mortality JAMA-J. Am. Med. Assoc. 288 988-95

[42] London J and Kelly J 1974 Global trends in total atmospheric ozone Science 184 987-9

[43] Wolkoff P 1995 Volatile organic compounds-sources, measurements, emissions, and the impact on indoor air quality. Indoor Air Indoor Air 5 5-73

[44] Brown S K, Sim M R, Abramson M J and Gray C N 1994 Concentration of volatile organic compounds in indoor air-a review Indoor Air 4 123-34

[45] Hodgson A T and Levin H 2003 Volatile organic compounds in indoor air: a review of concentrations measured in North America since 1990 Lawrence Berkeley National Lab Report LBNL-51715

[46] National Toxicology Program 2005 Report on Carcinogens, US Department of Health and Human Services, Public Health Service, Research Triangle Park, 13th edn

[47] Xu Y and Little J C 2006 Predicting emissions of SVOCs from polymeric materials and their interaction with airborne particles Environ. Sci. Technol. 40 456-61

[48] Weschler C J and Nazaroff W W 2008 Semivolatile organic compounds in indoor environments Atmos. Environ. 42 9018-40

[49] 2009 Executive Summary: 4th National Report on Human Exposure to Environmental Chemicals, Atlanta, GA: CDC (Centers for Disease Control and Prevention)

[50] Abt E, Suh H H, Catalano P and Koutrakis P 2000 Relative contribution of outdoor and indoor particle sources to indoor concentrations Environ. Sci. Technol. 34 3579-87

[51] Davitt K, Song Y K, Nurmikko A V, Jeon S R, Gherasimova M, Han J, Pan Y L and Chang R K 2005 UV LED arrays for spectroscopic fingerprinting of airborne biological particles Curr. Top. Solid State Phys. 2 2878-81

[52] Davitt K, Song Y-K, Patterson W R and Nurmikko A V 2005 290 and $340 \mathrm{~nm}$ UV LED arrays for fluorescence detection from single airborne particles Opt. Express 13 9548-55

[53] Chaplin W J, Elsworth Y, Isaak G R, Miller B A, New R and Pinter B 2005 Noise characteristics of full-disc helioseismic observations made by resonant scattering spectrometers Mon. Not. R. Astron. Soc. 359 607-14

[54] Bogumil K et al 2003 Measurements of molecular absorption spectra with the SCIAMACHY pre-flight model: instrument characterization and reference data for atmospheric remote-sensing in the $230-2380 \mathrm{~nm}$ region J. Photochem. Photobiol. A 157 167-84

[55] Thompson B A, Harteck P and Reeves R R Jr 1963 Ultraviolet absorption coefficients of $\mathrm{CO}_{2}, \mathrm{CO}, \mathrm{H}_{2} \mathrm{O}, \mathrm{N}_{2} \mathrm{O}, \mathrm{NH}_{3}, \mathrm{NO}$, $\mathrm{SO}_{2}$, and $\mathrm{CH}_{4}$ between 1850 and $4000 \AA \mathrm{J}$. Geophys. Res. 68 6431-6

[56] Daumont D, Brion J, Charbonnier J and Malicet J 1992 Ozone UV spectroscopy: I. Absorption cross-section at roomtemperature J. Atmos. Chem. 15 145-55
[57] Vandaele A C, Hermans C and Fally S 2009 Fourier transform measurements of $\mathrm{SO}_{2}$ absorptioncrosssections: II. Temperature dependence in the $29000-44000 / \mathrm{cm}$ (227-345 nm) region J. Quant. Spectrosc. Radiat. Transfer $1102115-26$

[58] Schneider W, Moortgat G K, Tyndall G S and Burrows J P 1987 Absorption cross-sections of $\mathrm{NO}_{2}$ in the UV and visible region (200-700 nm) at $298 \mathrm{~K}$ J. Photochem. Photobiol. A 40 195-217

[59] Magneron I, Thevenet R, Mellouki A and Le Bras G 2002 A study of the photolysis and $\mathrm{OH}$-initiated oxidation of acrolein and trans-crotonaldehyde J. Phys. Chem. A $1062526-37$

[60] Fahr A and Nayak A K 1994 Temperature dependent ultraviolet absorption cross sections of 1,3-butadiene and butadiyne Chem. Phys. 189 725-31

[61] Fihtengolts V S et al 1969 Atlas of UV Absorption Spectra of Substances Used in Synthetic Rubber Manufacture (New York: Plenum Press) p 171

[62] Cooper H R and Melville H W 1951 The kinetics of the autoxidation of n-decanal: I. The mechanism of reaction J. Chem. Soc. 1951 1984-93

[63] Au J W, Cooper G, Burton G R, Olney T N and Brion C E 1993 The valence shell photoabsorption of the linear alkanes, $\mathrm{CnH}_{2 n+2}(n=1-8)$ : absolute oscillator strengths (7-220 eV) Chem. Phys. 173 209-39

[64] Bolovinos A, Philis J, Pantos E, Tsekeris P and Andritsopoulos G 1982 The Methylebenzenes vis-a-vis Benzene J. Mol. Spectrosc. 94 55-68

[65] Bolovinos A, Philis J, Pantos E, Tsekeris P and Andritsopoulos G 1981 The methylebenzenes vis-a-vis benzene-comparison of their spectra in the Rydberg series region J. Chem. Phys. 75 4343-9

[66] Koban W, Koch J D, Hanson R K and Schulz C 2004 Absorption and fluorescence of toluene vapor at elevated temperatures Phys. Chem. Chem. Phys. 6 2940-5

[67] Etzkorn T, Klotz B, Sorensen S, Patroescu I V, Barnes I, Becker K H and Platt U 1999 Gas-phase absorption cross sections of 24 monocyclic aromatic hydrocarbons in the UV and IR spectral ranges Atmos. Environ. 33 525-40

[68] Kubala D et al 2009 Electron impact ionisation and UV absorption study of alpha - and beta-pinene Int. J. Mass Spectrom. 280 169-73

[69] Simon P C, Gillotay D, Vanlaethemmeuree N and Wisemberg J 1988 Temperature-dependence of ultravioletabsorption cross-section of chlorofluoroethanes Annal. Geophys.-Atmos. Hydrospheres Space Sci. 6 239-48

[70] Scharping H Z C 1985 Substituent effects in the VUV absorption-spectra of monochlorobenzene and orthodichlorobenzene, meta-dichlorobenzene and paradichlorobenzene J. Mol. Spectrosc. 112 8-17

[71] Au J W, Burton G R and Brion C E 1997 Quantitative spectroscopic studies of the valence-shell electronic excitation of Freons (CFC13, CF2C12, CF3C1, and CF 4) in the VUV and soft x-ray regions Chem. Phys. 221 151-68

[72] Hubrich C, Zetzsch C and Stuhl F 1977 Absorption-spectra of halogenated methanes in wavelength region from 275 to $160 \mathrm{~nm}$ at temperatures of 298 and 208 K Ber. BundenGes.-Phys. Chem. Chem. Phys. 81 437-42

[73] Doucet J, Sauvageau P and Sandorfy C 1975 Photoelectron and far Ultravoplet absorption-spectra of chlorofluoro derivatives of ethane J. Chem. Phys. 62 355-9

[74] Bartecki A, Szoke J, Varasanyi G and Vizesy M 1965 Absorption Spectra in the Ultraviolet and Visible Region vol 6 (New York: Academic)

[75] Lang L (ed) 1967 Absorption Spectra in the Ultraviolet and Visible Region (London: Academic) 
[76] Stuts J, Kim E S, Platt U, Bruno P, Perrino C and Febo A 2000 UV-visible absorption cross section of nitrous acid J. Geophys. Res. 105 14585-92

[77] Schneider W and Moortgat G 1997 personal communication to Röth E P, Ruhnke R, Moortgat G, Meller R and Schneider W, Berichte des Forschungszentums Jülich, jül-3341

[78] Plagens H, Bröske R, Spittler M, Ruppert L, Barnes I and Becker H K 1998 Atmospheric loss processes of hexanal. Photolysis and reaction with $\mathrm{OH}$ and $\mathrm{Cl}$ radicals Proc. 2nd Workshop of the EUROTRAC-2 Subproject Chemical Mechanism Development (Karlsruhe, Germany) GPP10-1-GPP10-4

[79] Hodgkinson J, Smith R, Ho W O, Saffell J R and Tatam R P 2012 A low cost, optically efficient carbon dioxide sensor based on non-dispersive infra-red (NDIR) measurement at $4.2 \mu \mathrm{m}$ Proc SPIE 8439843919
[80] Edmund Optics NT47-612, Technical Data Sheet, Edmund Optics Inc., Barrington, USA

[81] Saraga D, Pateraki S, Papadopoulos A, Vasilakos C and Maggos T 2011 Studying the indoor air quality in three non-residential environments of different use: a museum, a printery industry and an office Build. Environ. 46 2333-41

[82] Peng C Y, Lan C H and Wu T J 2009 Investigation of indoor chemical pollutants and perceived odor in an area with complaints of unpleasant odors Build. Environm. 44 2106-13

[83] Marchand C, Bulliot B, Le Calve S and Mirabel P 2006 Aldehyde measurements in indoor environments in Strasbourg (France) Atmos. Environ. 40 1336-45

[84] Shaughnessy R J, McDaniels T J and Weschler C J 2001 Indoor chemistry: ozone and volatile organic compounds found in tobacco smoke Environ. Sci. Technol. 35 2758-64 
2015-12-14

\section{A measurement strategy for} non-dispersive ultra-violet detection of formaldehyde in indoor air: Spectral analysis and interferent gases

Davenport, John

Institute of Physics

J J Davenport et al 2016 Meas. Sci. Technol. 27015802

http://dx.doi.org/10.1088/0957-0233/27/1/015802

Downloaded from Cranfield Library Services E-Repository 